\title{
Clinical analysis and RNA findings in a family with SARS-CoV-2 infection: Case reports
}

\author{
FEN LIN $^{1 *}$, YONG-HAO WU ${ }^{*}$, WEN-JIAN DENG ${ }^{2 *}$, PEI-BIAO WU ${ }^{3}$, JIAN-YONG CHEN ${ }^{4}$, SHAO-HUANG TANG $^{3}$, \\ JIN-ZHOU WEN ${ }^{3}$, SHAO-QUN LIU ${ }^{3}$, ZHUO-MAO LIN ${ }^{5}$, DENG-FENG LI ${ }^{3}$, JIN-SHENG CHEN ${ }^{6}$, WEI-ZHAO CHEN ${ }^{2}$, \\ JIANG-FANG LU ${ }^{6}$, JIAN-WEN HONG ${ }^{6}$, JIN-PEI GAO ${ }^{6}$, PENG-FEI XU ${ }^{6}$ and LI-YE YANG ${ }^{1}$ \\ ${ }^{1}$ Central Laboratory, and ${ }^{2}$ Department of Infection, Chaozhou Central Hospital Affiliated to Southern \\ Medical University, Chaozhou, Guangdong 521021; ${ }^{3}$ Chaozhou Center for Disease Control and Prevention, \\ Chaozhou, Guangdong 521099; Departments of ${ }^{4}$ Respiration, ${ }^{5}$ Radiology and ${ }^{6}$ Medicine, Chaozhou Central \\ Hospital Affiliated to Southern Medical University, Chaozhou, Guangdong 521021, P.R. China
}

Received May 8, 2020; Accepted June 23, 2020

DOI: $10.3892 /$ wasj.2020.58

\begin{abstract}
The present study reported the epidemiological, clinical features, laboratory data and management of a family of 5 members with COVID-19. It was found that the initial clinical manifestations of the 3 adults were fever, cough and sore throat; they all exhibited a higher erythrocyte sedimentation rate (ESR) and higher serum glucose level. The 2 children only exhibited a mild dry cough. As regards the 2-month-old infant who was breast-fed, the possible infection source was close contact with family members or respiratory droplets. Her mother's breast milk was negative for SARS-CoV-2, as shown by RT-PCR. The two children persisted to be positive for SARS-CoV-2 by anal swab after being released from the hospital, although they were negative for SARS-CoV-2 by a throat swab.
\end{abstract}

\section{Introduction}

The 2020 Spring Festival was unusual for China, and a large-scale novel coronavirus pneumonia outbreak occurred in Wuhan, Hubei, a city in South Central China on the Yangtze River $(1,2)$. This novel coronavirus was named severe acute respiratory syndrome coronavirus 2 (SARS-CoV-2), and the associated pneumonia was designated as COVID-19 by the World Health Organization (WHO). Since the first 4 cases were reported on December 29, 2019, the virus

Correspondence to: Dr Li-Ye Yang, Central Laboratory, Chaozhou Central Hospital Affiliated to Southern Medical University, 84 Huan-Cheng-Xi Road, Chaozhou, Guangdong 521021, P.R. China E-mail: yangleeyee@sina.com

*Contributed equally

Key words: severe acute respiratory syndrome coronavirus 2, COVID-19, family cluster, RNA rapidly spread throughout China and numerous countries worldwide $(3,4)$.

SARS-CoV-2 is a $\beta$ coronavirus ( $\beta \mathrm{CoV}$ ) that is usually polymorphous with a diameter varying from approximately 60 to $140 \mathrm{~nm}$. The genome has a $89 \%$ nucleotide identity to bat SARS-like-CoVZXC21 and a $82 \%$ identity to human SARS-CoV (5). The virus spreads from individual to individual by close contact and via respiratory droplets. Based on the current epidemiological surveys, the incubation period is 1-14 days, mostly 3-7 days. For confirmed SARS-CoV-2 infections, the reported illnesses range from asymptomatic or mild to severe and even fatal. Symptoms include fever, fatigue and cough. The progression of the illness in some patients is rapid, and they exhibit shortness of breath, hypoxemia, acute respiratory distress syndrome (ARDS), metabolic acidosis, renal failure and coagulation dysfunction $(6,7)$.

Guangdong Province was also threatened by the SARS-CoV-2 infection. Geographically, Chaozhou is an Eastern city in Guangdong and is $>1,000 \mathrm{~km}$ away from Wuhan. In the present study, the first cluster of SARS-CoV-2 infection was investigated in a family derived from Wuhan.

\section{Case reports}

The study subjects were a family of 5 members (husband, 36 years old; wife, 31 years old; mother-in-law, 53 years old; son and daughter, aged 8 years and 2 months, respectively) who visited relatives in Chaozhou by driving in a car from Wuhan on January 25, 2020 and arrived in Chaozhou on the same day, and then checked into a hotel. None of the family members had a contact history with the South China Seafood Whole Sale Market or animals in Wuhan. In total, 3 family members (husband, mother-in-law and wife) visited the outpatient clinic at hospital due to respiratory symptoms on January 29. The husband, wife and mother-in-law were identified with multifocal patchy ground-glass opacity by a chest CT scan (Fig. 1). Throat swab specimens from this family were obtained and sent for the detection of SARS-CoV-2 by reverse transcription-polymerase chain reaction (RT-PCR) assays; the 3 adults and the boy were 
found to be positive. The female infant was negative for SARS-CoV-2 on the same day, and was subsequently diagnosed with SARS-CoV-2 infection 4 days later. They were admitted to Chaozhou Central Hospital for isolation and treatment.

The present study was approved by the Institutional Review Board of Chaozhou Central Hospital. The study-related information was acquired following consultation with the patients or their guardians.

Upon admission, the 3 adults had fever accompanied by a cough and sore throat, whereas the 2 children only exhibited a mild dry cough. The husband also experienced expectoration, transient chest pain and general fatigue symptoms. The erythrocyte sedimentation rate (ESR) and serum glucose levels were increased in the 3 adults. The wife was currently in the lactation period; her major clinical manifestation was recurrent and she sustained fever until the 7 th day after admission, and her highest recorded temperature was $39.4^{\circ} \mathrm{C}$. In addition, 2 RT-PCR tests for SARS-CoV-2 performed on her breast milk were negative.

The laboratory results of the mother-in-law also displayed elevated levels of creatine kinase and C-reactive protein; she was not known to suffer from any underlying diseases. As her oxygen saturation fell to $90 \%$, she was transferred to the intensive care unit (ICU) and administered non-invasive mechanical ventilation. On the 18th day following her admission, her oxygen saturation values improved to $96 \%$, and subsequently, she recovered and was discharged with a better prognosis.

The infant was breastfeeding before her mother was diagnosed with SARS-CoV-2 infection. To date, she is the youngest COVID-19 patient in Guangdong, and her infection source was possibly the close contact she had with her family members.

The clinical features and laboratory data of these 5 patients with COVID-19 are summarized in Tables I and II. According to the SARS-CoV-2 guidelines (Trial Version 6) (7), the mother-in-law was categorized as having the severe type, the husband and the wife had the common type, and the son and daughter had the mild type of infection. The elder sister of the husband, who had close contact with this family and 33 other common contacts, was placed into quarantine and isolated for medical surveillance. To date, no SARS-CoV-2 infection has been detected in these contacts.

The 3 adults were administered a combination therapy of antivirals and antibiotics successively, including Oseltamivir, kaletra, recombinant human interferon $\alpha-2 b$, thymalfasin and human immunoglobulin. They were also treated with methylprednisolone, and no short-term adverse effects were identified. The 2 children received general care. The medications of the patients are presented in Table III.

Following 2 successive negative results (at intervals of at least $24 \mathrm{~h}$ ) for SARS-CoV-2 RNA by throat and anal swabs, $\mathrm{CT}$ imaging showing that the virus infection was no longer present, and normal temperatures for at least 3 days, they were discharged from the hospital and returned to their residence for prolonged isolation under medical surveillance. However, the boy and the infant tested positive for SARS-CoV-2 by anal swabs on the 4th day following discharge, although their throat swabs were negative. The son reappeared with a mild
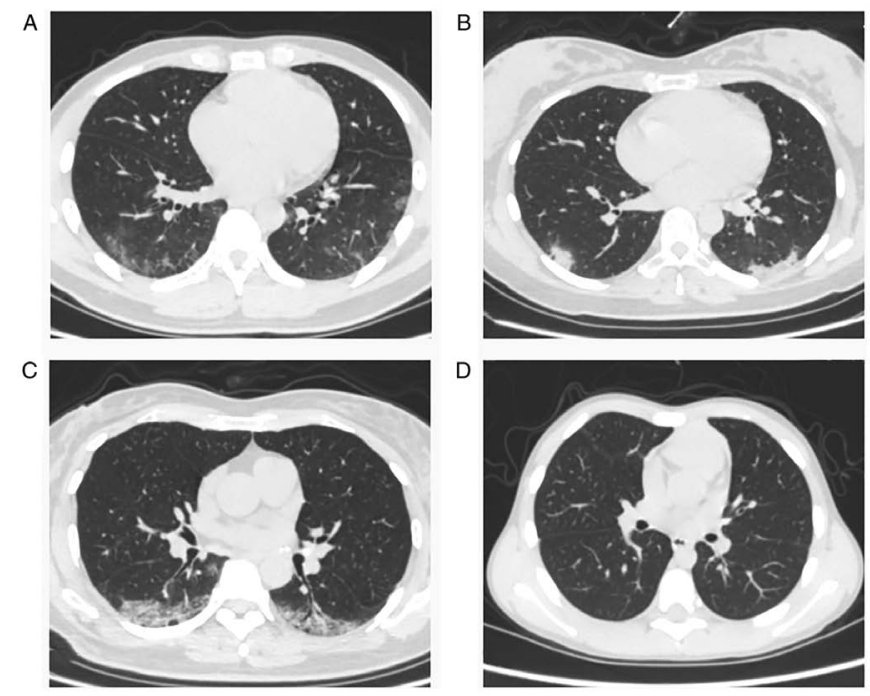

Figure 1. Chest CT imaging of patients infected with COVID-19. Axial thin-section non-contrast computed tomography (CT) scan shows bilateral ground-glass opacities with a pronounced peripheral distribution in (A) the husband, (B) the wife, and (C) the mother-in-law. (D) Normal chest CT scan from the boy.

fever of $37.6-38^{\circ} \mathrm{C}$, although no abnormal findings were found in the chest $\mathrm{CT}$ and routine blood tests. They continued to test positive for SARS-CoV-2 RNA by anal swabs for half a month. The results of RT-PCR assays for the SARS-CoV-2 are presented in Table IV.

\section{Discussion}

Beginning in December, 2019, multiple cases of pneumonia caused by an unknown pathogen associated with a market selling seafood and wild animals at Wuhan were reported. The pathogen was found to be a novel coronavirus (SARS-CoV-2) $(6,8)$. Cases have now spread throughout China, including Guangdong Province. The first case in Guangdong was reported from Shenzhen on January 19, and a 66-year-old male was confirmed with COVID-19 after visiting Wuhan (9).

The present study reports the first SARS-CoV-2 confirmed family cluster in Chaozhou, Eeastern Guangdong Province. The family originally resided in Wuhan, China, but claimed that they had not visited the seafood wholesale market, or any medical institutions or had any contact with any fever patients during their stay in Wuhan. Although the origin of this SARS-CoV-2 infection is unknown, the evidence for human-to-human transmission is clear $(6-8,10)$. To date, no further cases of SARS-CoV-2 related to this family have been reported.

Among the 5 cases in this family, the 8-year-old boy and the 2-month-old girl exhibited only a slight cough, with no fever or pneumonia. The 3 adults exhibited apparent pneumonia. It seemed that the younger patient was less likely to be infected and had mild symptoms of subclinical syndrome. COVID-19 cases in children have rarely been reported to date. A previous study from Wuhan described 9 infants infected with SARS-CoV-2, none of whom required intensive care or mechanical ventilation or had any 
Table I. The physical examination and clinical symptom data for the 1st day of admission.

\begin{tabular}{|c|c|c|c|c|c|}
\hline Characteristic & Case 1 & Case 2 & Case 3 & Case 4 & Case 5 \\
\hline Sex & Male & Female & Female & Male & Female \\
\hline Age & 36 years & 31 years & 53 years & 8 years & 2 months \\
\hline Body temperature $\left({ }^{\circ} \mathrm{C}\right)$ & 37.2 & 37.5 & 37.7 & 36.4 & 36.8 \\
\hline Pulse (per min) & 84 & 84 & 92 & 94 & 140 \\
\hline Respiratory rate (per min) & 18 & 17 & 20 & 22 & 30 \\
\hline Blood pressure (mmHg) & $132 / 80$ & $120 / 85$ & $132 / 84$ & $100 / 70$ & - \\
\hline Blood oxygen saturation (\%) & 99 & 99 & 99 & 97 & 99 \\
\hline Fever & + & + & + & - & - \\
\hline Cough & + & + & + & + & + \\
\hline Sore throat & + & + & + & - & NA \\
\hline Expectoration & + & - & - & - & - \\
\hline Chest pain & + & - & - & - & - \\
\hline General fatigue & + & - & - & - & NA \\
\hline
\end{tabular}

+ , Positive; -, negative; NA, not available.

severe complications (11). In that study, 34 cases of children were categorized into $22(65 \%)$ common, 9 (26\%) mild and $3(8.8 \%)$ asymptomatic cases in a study from Shenzhen (11). No severe or critical cases were identified. The clinical manifestations in children with SARS-CoV-2 infection are non-specific and are milder than those in adults (12). To date, the relatively low infection rate in children may be explained by the following issues: i) Children are not prone to SARS-CoV-2 infection, and only a few children are infected when they encounter SARS-CoV-2; ii) most children with SARS-CoV-2 infection exhibit the mild syndrome or cryptic infection as in the cases in the present study, and they cannot easily be identified by health care providers or public health authorities.

The reasons why children would be less severely affected by SARS-CoV-2 are unclear. One possible reason is related to their prior exposure to other respiratory viruses, such as influenza, rendering their immune systems more resilient (13). Another hypothesis that has been proposed is that young children are not capable of mobilizing a peak mature immune response, as commonly observed in adults during the immune dysregulation phase; thus, less organ damage ensues, with its associated morbidity and mortality $(13,14)$.

Overall, the genome of SARS-CoV-2 has $82 \%$ nucleotide identity with that of human severe acute respiratory syndrome (SARS)-associated coronavirus (SARS-CoV), which was the causal agent of the SARS outbreaks in 2003 in Guangdong Province and Hongkong (5). These 2 types of coronavirus belong to the same $\beta$ coronavirus genus (5). Both SARS-CoV (lineage $\mathrm{B} \beta \mathrm{CoV}$ ) and SARS-CoV-2 cause severe lower respiratory tract infection and extrapulmonary manifestations, such as diarrhea, lymphopenia, liver dysfunction and multiorgan dysfunction. Based on a retrospective analysis, $<10 \%$ of SARS-CoV infections occurred in children. Among the affected children, only $5 \%$ required admission to an intensive care unit, and $<1 \%$ required mechanical ventilation. No deaths were reported among the children affected by SARS-CoV (13). In contrast to its adult counterpart, the clinical course of affected children is usually milder, and the time to resolution is shorter. The similarity of these 2 viruses led us to believe that SARS-CoV-2 is also a relatively mild disease among children.

The 2 children of the family presented herein were confirmed to have SARS-CoV-2 infection as they were from Wuhan and were continually monitored after they arrived at Chaozhou. If they had not reported their journey, the mildness of their syndromes may have made them unnoticeable to public health authorities; they would become SARS-CoV-2 carriers and would have transmitted the virus to those who came into close contact with them. These cryptic cases, or walking carriers, may serve as possible infection sources to propagate the outbreak (7). Therefore, attention should be paid to asymptomatic cases, which may play a critical role in the transmission process. It is still crucial to isolate patients and to trace and quarantine suspected subjects as early as possible; suspected cases should be isolated in a single room following doctors' advice, and self-isolation at home should not be encouraged due to the danger of cluster infection (7). Further studies on the epidemiological significance of these asymptomatic cases are warranted.

The 5 members of the family presented herein were all infected with SARS-CoV-2, which indicated the potent transmission capacity of this new virus (15). This virus is a new type of coronavirus; thus, individuals generally lack immunity to this virus and are susceptible to infection. A close relative (sister-in-law) who had taken care of the infant was not infected in the present study, as confirmed by 2 RT-PCR measurements. The explanation for this was either that the quantity of the virus from the infant was not sufficient or that the immune function of the exposed relative was strong enough to resist infection.

There was a lactating mother in the present study. Her milk was collected and tested for SARS-CoV-2 infection, and 
Table II. Summary of the laboratory results of the family cluster infected with SARS-CoV-2.

\begin{tabular}{|c|c|c|c|c|c|c|}
\hline Characteristic & Reference range & Husband & Wife & Mother-in-law & Boy & Girl \\
\hline Sex & - & Male & Female & Female & Male & Female \\
\hline Age & - & 36 years & 31 years & 53 years & 8 years & 2 months \\
\hline \multicolumn{7}{|l|}{ RT-PCR } \\
\hline ORF1ab & - & $+(\mathrm{Ct} 36.6)$ & $+(\mathrm{Ct} 26.8)$ & $+(\mathrm{Ct} 33.6)$ & $+(\mathrm{Ct} 36.1)$ & $+(\mathrm{Ct} 36.9)$ \\
\hline $\mathrm{N}$ gene & - & $+(\mathrm{Ct} 38.0)$ & $+(\mathrm{Ct} 29.3)$ & $+(\mathrm{Ct} 35.2)$ & $+(\mathrm{Ct} 37.0)$ & $+(\mathrm{Ct} 37.3)$ \\
\hline White blood cell count $\left(10^{9} / 1\right)$ & $3.5-9.5$ & 3.69 & 6.73 & 6.26 & 6.03 & - \\
\hline Red blood cell count $\left(10^{12} / 1\right)$ & $3.8-5.1^{\mathrm{a}} / 4.3-5.8^{\mathrm{b}}$ & 4.82 & 4.4 & 4.34 & 4.41 & - \\
\hline Absolute neutrophil count $\left(10^{9} / 1\right)$ & $1.8-6.3$ & 2.21 & 4.72 & 4.76 & 3.44 & - \\
\hline Absolute lymphocyte count $\left(10^{9} / 1\right)$ & $1.1-3.2$ & 1.17 & 1.51 & 1.07 & 1.98 & - \\
\hline Hematocrit & $0.35-0.45^{\mathrm{a}} / 0.40-0.50^{\mathrm{b}}$ & 0.421 & 0.424 & 0.407 & 0.379 & - \\
\hline Hemoglobin $(\mathrm{g} / \mathrm{l})$ & $115-150^{\mathrm{a}} / 130-175^{\mathrm{b}}$ & 145 & 141 & 139 & 131 & - \\
\hline Platelet count $\left(10^{9} / 1\right)$ & $125-350$ & 144 & 274 & 145 & 312 & - \\
\hline Calcium (mmol/l) & $2.08-2.60$ & 2.2 & 2.37 & 2.18 & 2.26 & - \\
\hline Sodium (mmol/l) & $137-147$ & 136.4 & 136.4 & 139.2 & 139 & - \\
\hline Potassium (mmol/1) & $3.5-5.3$ & 3.62 & 4.21 & 3.56 & 3.7 & - \\
\hline Chloride (mmol/l) & $99-110$ & 101.8 & 98.2 & 101.7 & 99.2 & - \\
\hline Total carbon dioxide (mmol/l) & $22-29$ & 23.7 & 23.8 & 23.5 & 29.5 & - \\
\hline Glucose (mmol/l) & $3.90-6.10$ & 6.62 & 6.37 & 7.78 & 6 & - \\
\hline Blood urea nitrogen (mmol/l) & $1.8-8.2$ & 2.68 & 2.82 & 2.7 & 3.24 & - \\
\hline Creatinine $(\mu \mathrm{mol} / \mathrm{l})$ & $41-115^{\mathrm{a} / 53}-115^{\mathrm{b}}$ & 73 & 68 & 73 & 47 & - \\
\hline Total protein $(\mathrm{g} / \mathrm{l})$ & $65-85$ & 74.2 & 86.6 & 78.4 & 79.6 & - \\
\hline Albumin (g/l) & $40-55$ & 46 & 48.1 & 44.8 & 46.9 & - \\
\hline Total bilirubin $(\mu \mathrm{mol} / \mathrm{l})$ & $3.4-26.0$ & 7.52 & 3.28 & 4.06 & 4.99 & - \\
\hline Procalcitonin (ng/ml) & $<0.1$ & 0.05 & 0.05 & 0.05 & 0.18 & - \\
\hline Alanine aminotransferase (U/l) & $7-40^{\mathrm{a}} / 9-50^{\mathrm{b}}$ & 22 & 50 & 18 & 20 & - \\
\hline Aspartate aminotransferase (U/l) & $13-35^{\mathrm{a}} / 15-40^{\mathrm{b}}$ & 21 & 42 & 25 & 25 & - \\
\hline Alkaline phosphatase (U/l) & $50-135^{\mathrm{a}} / 45-125^{\mathrm{b}}$ & 66 & 162 & 72 & $242^{c}$ & - \\
\hline Lactate dehydrogenase (U/l) & $0-247^{\mathrm{a}} / 0-248^{\mathrm{b}}$ & 184 & 259 & 213 & 217 & - \\
\hline Creatine kinase (U/l) & $26-174$ & 154 & 82 & 205 & 78 & - \\
\hline Creatine kinase isoenzyme (U/l) & $0-24$ & 10.8 & 14.6 & 11.4 & 12.5 & - \\
\hline Myoglobin $(\mu \mathrm{g} / \mathrm{l})$ & $0-106^{\mathrm{a}} / 0-154.9^{\mathrm{b}}$ & 30.7 & 16.4 & 30.8 & - & - \\
\hline High sensitive cardiac troponin-I $(\mu \mathrm{g} / \mathrm{l})$ & $0-0.0156^{\mathrm{a}} / 0-0.0342^{\mathrm{b}}$ & 0.001 & 0.001 & 0.001 & - & - \\
\hline C-reactive protein (mg/l) & $0-8.0$ & 6.7 & 7.3 & 18.3 & 4.42 & - \\
\hline Fibrinogen $(\mathrm{g} / \mathrm{l})$ & $2-4$ & 2.95 & 2.91 & 2.95 & - & - \\
\hline Prothrombin time (sec) & $9.00-12.8$ & 11.8 & 12 & 11.5 & - & - \\
\hline International normalized ratio & - & 1.07 & 1.09 & 1.04 & - & - \\
\hline D-Dimer $(\mu \mathrm{g} / \mathrm{ml})$ & $<0.5$ & 0.11 & 0.07 & 0.15 & - & - \\
\hline Erythrocyte sedimentation rate $(\mathrm{mm} / \mathrm{h})$ & $0-20^{\mathrm{a}} / 0-15^{\mathrm{b}}$ & 35 & 24 & 32 & - & - \\
\hline
\end{tabular}

+ , Positive; -, data not available. ${ }^{\mathrm{a}}$ female's reference range; ${ }^{\mathrm{b}}$ male's reference range; ${ }^{\mathrm{c}}$ children's alkaline phosphatase reference range is $104-345$ $\mathrm{U} / 1$. Ct value $<43$ was defined as a positive test. ORF1ab, open reading frame $1 \mathrm{a}$ or $1 \mathrm{~b}$; $\mathrm{N}$ gene, nucleocapsid protein gene.

no viral RNA was detected in the milk by RT-PCR. Either the low level of the virus could not reach our detection limit (1,000 copies/ml), or no virus was present in the milk. Further studies are required to determine whether SARS-CoV-2 is secreted in the milk of infected mothers and, if so, to determine whether consuming breast milk is associated with SARS-CoV-2 infection in infants. In the family of the present study, the infant lived with her mother and was breast-fed, and the most likely transmission method for the infant was close contact within the household. The mother was persuaded to terminate breast feeding after her SARS-CoV-2 infection was confirmed, and if necessary, theoretically, the pasteurization of the mother's milk could prevent SARS-CoV-2 transmission if the infant needed her mother's milk. There were several cases of pregnancy in the 2003 outbreak of SARS-CoV, and no report has indicated the presence of the virus in the milk of infected mothers (16).

The nucleic acids of SARS-CoV-2 were detected in stool samples in an early study (17). Another study found that 8 of 


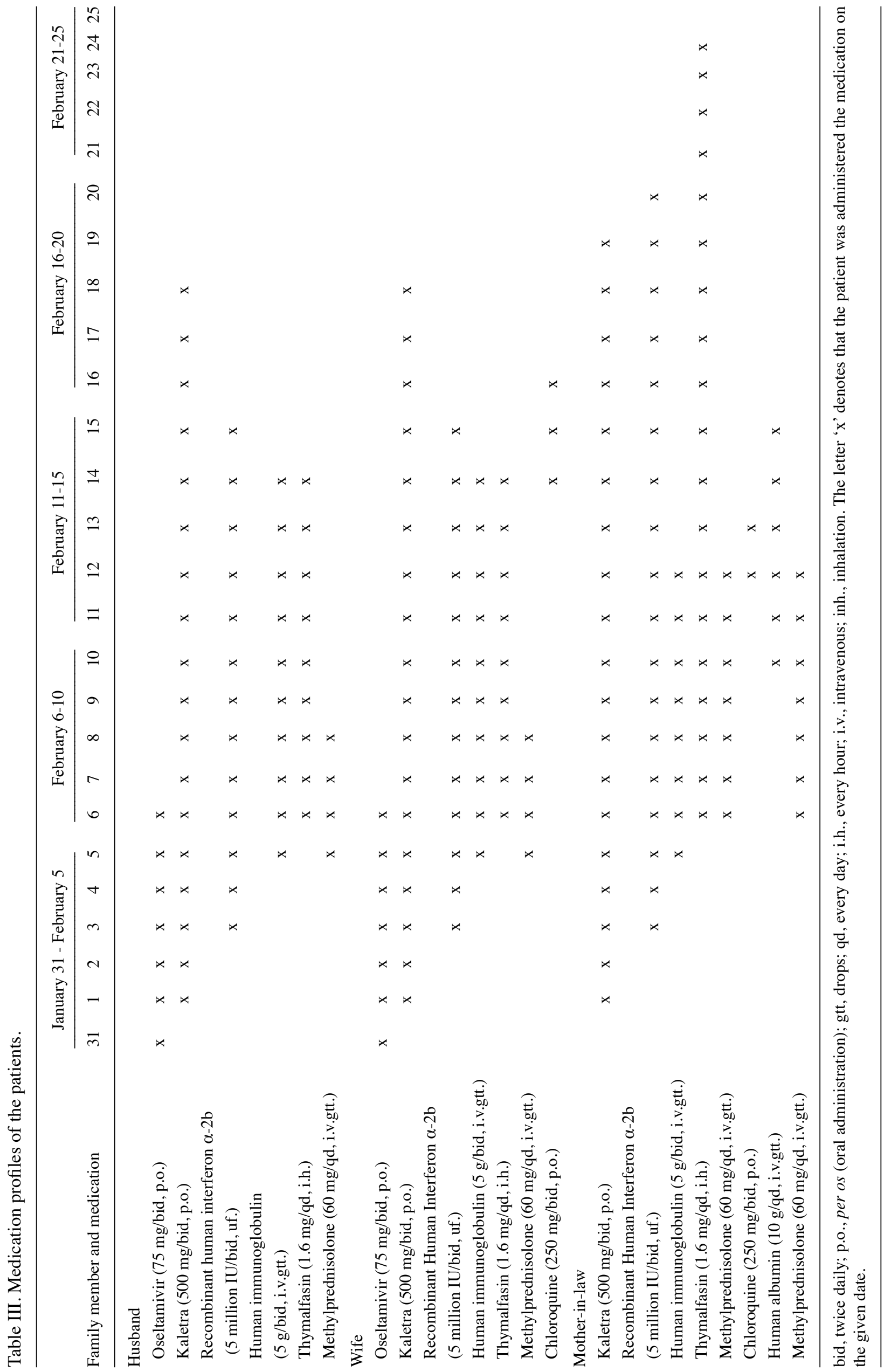


Table IV. Results of RT-PCR testing for the SARS-CoV-2.

\begin{tabular}{|c|c|c|c|c|c|c|c|c|c|c|}
\hline \multirow[b]{2}{*}{ Date } & \multicolumn{2}{|c|}{ Husband } & \multicolumn{2}{|c|}{ Wife } & \multicolumn{2}{|c|}{ Mother-in-law } & \multicolumn{2}{|c|}{ Boy } & \multicolumn{2}{|c|}{ Girl } \\
\hline & Throat & Anal & Throat & Anal & Throat & Anal & Throat & Anal & Throat & Anal \\
\hline January 30 & + & & + & & + & NT & - & NT & NT & NT \\
\hline January 31 & NT & NT & NT & NT & NT & NT & + & NT & - & NT \\
\hline February 2 & NT & NT & NT & NT & NT & NT & NT & $\mathrm{NT}$ & + & NT \\
\hline February 7 & NT & NT & NT & NT & NT & NT & - & NT & NT & NT \\
\hline February 11 & NT & NT & NT & NT & NT & NT & - & NT & NT & NT \\
\hline February 12 & NT & NT & NT & NT & NT & NT & - & NT & NT & NT \\
\hline February 13 & - & NT & \pm & NT & NT & NT & - & NT & NT & NT \\
\hline February 14 & & NT & NT & NT & NT & NT & NT & NT & - & + \\
\hline February 15 & - & NT & - & NT & NT & NT & \multicolumn{2}{|c|}{ Discharge } & NT & NT \\
\hline February 17 & - & - & - & - & NT & NT & NT & NT & \multicolumn{2}{|c|}{ Discharge } \\
\hline February 18 & \multicolumn{2}{|c|}{ Discharge } & \multicolumn{2}{|c|}{ Discharge } & NT & NT & NT & $\mathrm{NT}$ & NT & NT \\
\hline February 19 & NT & NT & NT & NT & - & - & NT & NT & NT & NT \\
\hline February 20 & NT & NT & NT & NT & NT & NT & - & + & NT & NT \\
\hline February 21 & - & - & - & - & - & - & - & + & NT & + \\
\hline February 22 & NT & NT & NT & NT & NT & NT & NT & NT & NT & + \\
\hline February 23 & NT & NT & NT & NT & - & - & - & + & NT & NT \\
\hline February 24 & - & - & - & - & NT & NT & NT & NT & NT & NT \\
\hline February 25 & NT & NT & NT & NT & NT & NT & - & - & NT & NT \\
\hline February 26 & NT & NT & NT & NT & - & - & - & - & NT & NT \\
\hline February 28 & NT & NT & NT & NT & \multicolumn{2}{|c|}{ Discharge } & - & - & NT & NT \\
\hline March 1 & - & - & - & - & - & - & - & + & - & + \\
\hline
\end{tabular}

+, Positive; -, negative; NT, not tested.

the 11 patients who were positive for the virus by anal swab had a severe clinical manifestation (18). The 2 children of the present study were detected with SARS-CoV-2 by anal swabs after they were released from the hospital, although they had no diarrhea. This suggested 2 possibilities: One explanation was that the detected targets were decomposed fragments of dead SARS-CoV-2, which could not cause disease; the other explanation was that the virus could proliferate in the digestive tract, was alive in the anal swab, and had transmission potential in humans (19). The second explanation appeared more substantial as dead virus RNA could not persist for a long time after the viruses degraded. This issue needs to be clarified further.

Despite the worsening trends of COVID-19, no drugs have been proven to have significant efficacy in the clinical treatment of patients with COVID-19. Remdesivir was considered the most promising antiviral agent for COVID-19; it functions by inhibiting the activity of RNA-dependent RNA polymerase. In a recent study of adult patients with severe COVID-19, remdesivir was not associated with any significant clinical benefits. However, it shortened the time for clinical improvement (20). The protease inhibitor lopinavir/ritonavir (LPV/RTV) alone is not shown to provide better antiviral efficacy than standard care (20). However, the regimen of LPV/RTV plus ribavirin was shown to be effective against SARS-CoV in vitro. The regimen of LPV/RTV was applied for the 3 adult patients in the present study, and better results were obtained; however, the limited number of cases in the present study was not sufficient to reach a conclusion; thus, the measurement of the efficacy requires ongoing randomized, placebo-controlled trials.

Cluster infection is common in SARS-CoV-2 $(11,12)$; the gathering of individuals was the main form of transmission. Therefore, vigilant control is warranted at this early stage of the pandemic. At the time of the writing of this manuscript, authorities have closed public transit and have canceled outbound transportation (train, air and long-distance buses) in several cities of Hubei. Vehicular traffic in large cities, such as Wuhan, Wenzhou, Hangzhou, Shanghai and Shenzhen was discouraged. China has also imposed a ban on overseas travel with tour groups and has suspended the sale of flight and hotel packages. These measures were shown to be successful as the number of newly confirmed cases has apparently decreased in China for the past 2 months (21).

\section{Acknowledgements}

Not applicable.

\section{Funding}

The present study was funded by the Special Research Plan SARS-CoV-2 of Chaozhou (2020xg01) and the Natural Science 
Foundation of Guangdong Province (2016A030307035) to LYY.

\section{Availability of data and materials}

All data generated or analyzed during this study are included in this published article or are available from the corresponding author on reasonable request.

\section{Authors' contributions}

LYY and FL had roles in the study design, data collection, and writing of the manuscript. WJD, WZC and JYC were involved in clinical management. YHW contributed to writing of the report. PBW, SHT, JZW, SQL and DFL provided and interpreted the data. ZML, JSC, JFL, JWH, JPG and PFX contributed to the data analysis. All authors reviewed and approved the final version of the manuscript.

\section{Ethics approval and consent to participate}

The present study was approved by the Institutional Review Board of Chaozhou Central Hospital. The study-related information was acquired following consultation with the patients or their guardians.

\section{Patient consent for publication}

Written consent forms were obtained from all patients, and informed consents were signed or thumb printed by the participants or their guardians.

\section{Competing interests}

All authors declare that they have no competing interests.

\section{References}

1. World Health Organization. Pneumonia of unknown cause-China https://www.who.int/csr/don/05-january-2020-pneumonia-of-unkowncause-china/en/. Accessed January 5, 2020.

2. WHO. Novel coronavirus-China. January 12, 2020. http://www. who. int/csr/don/12-january-2020-novel-coronavirus-china/en/. Accessed January 19, 2020.

3. Tan WJ, Zhao X and Ma XJ: A novel coronavirus genome identified in a cluster of pneumonia cases: Wuhan, China 2019-2020. China CDC Weekly 2: 61-62, 2020.

4. Ahn DG, Shin HJ, Kim MH, Lee S, Kim HS, Myoung J, Kim BT and Kim SJ: Current status of epidemiology, diagnosis, therapeutics, and vaccines for novel coronavirus disease 2019 (COVID-19). J Microbiol Biotechnol 30: 313-324, 2020.

5. Chan JF, Kok KH, Zhu Z, Chu H, To KK, Yuan S and Yuen KY: Genomic characterization of the 2019 novel human-pathogenic coronavirus isolated from a patient with atypical pneumonia after visiting Wuhan. Emerg Microbes Infect 9: 221-236, 2020.
6. Huang C, Wang Y, Li X, Ren L, Zhao J, Hu Y, Zhang L, Fan G, Xu J, Gu X, et al: Clinical features of patients infected with 2019 novel coronavirus in Wuhan, China. Lancet 395: 497-506, 2020.

7. China National Health Commission: Diagnosis and treatment of pneumonitis caused by new coronavirus (trial version 6). Beijing: China National Health Commission, 2020. http://www.nhc.gov. cn/xcs/zhengcwj/202002/8334a8326dd94d329df351d7da8aefc2. shtm.

8. Zhu N, Zhang D, Wang W, Li X, Yang B, Song J, Zhao X, Huang B, Shi W, Lu R, et al: A novel coronavirus from patients with pneumonia in China, 2019. N Engl J Med 382: 727-733, 2020.

9. http://wsjkw.gd.gov.cn/xxgzbdfk/content/post_2880738.html.

10. Special Expert Group for Control of the Epidemic of Novel Coronavirus Pneumonia of the Chinese Preventive Medicine Association: An update on the epidemiological characteristics of novel coronavirus pneumonia (COVID-19). Zhonghua Liu Xing Bing Xue Za Zhi 41: 139-144, 2020 (In Chinese).

11. Wei M, Yuan J, Liu Y, Fu T, Yu X and Zhang ZJ: Novel coronavirus infection in hospitalized infants under 1 year of age in China. JAMA 323: 1313-1314, 2020.

12. Wang XF, Yuan J, Zheng YJ, Chen J, Bao YM, Wang YR, Wang LF, Li H, Zeng JX, Zhang YH, et al: Retracted: Clinical and epidemiological characteristics of 34 children with 2019 novel coronavirus infection in Shenzhen. Zhonghua Er Ke Za Zhi 58: E008, 2020 (Epub ahead of print).

13. Li AM, Ng PC: Severe acute respiratory syndrome (SARS) in neonates and children. Arch Dis Child Fetal Neonatal Ed 90: F461-F465, 2005.

14. Hon KL, Leung CW, Cheng WT, Chan PK, Chu WC, Kwan YW, Li AM, Fong NC, Ng PC, Chiu MC, et al: Clinical presentations and outcome of severe acute respiratory syndrome in children. Lancet 361: 1701-1703, 2003.

15. Wu JT, Leung $\mathrm{K}$ and Leung GM: Nowcasting and forecasting the potential domestic and international spread of the 2019-nCoV outbreak originating in Wuhan, China: A modelling study. Lancet 395: 689-697, 2020.

16. Shek CC, Ng PC, Fung GP, Cheng FW, Chan PK, Peiris MJ, Lee KH, Wong SF, Cheung HM, Li AM, et al: Infants born to mothers with severe acute respiratory syndrome. Pediatrics 112: e254, 2003 .

17. Holshue ML, DeBolt C, Lindquist S, Lofy KH, Wiesman J, Bruce H, Spitters C, Ericson K, Wilkerson S, Tural A, et al: First case of 2019 novel coronavirus in the United States. N Engl J Med 382: 929-936, 2020.

18. Chen W, Lan Y, Yuan X, Deng X, Li Y, Cai X, Li L, He R, Tan Y, Deng X, et al: Detectable 2019-nCoV viral RNA in blood is a strong indicator for the further clinical severity. Emerg Microbes Infect 9: 469-473, 2020.

19. Zhang Y, Chen C, Zhu S, Shu C, Wang D, Song J, Song Y, Zhen W, Feng Z, Wu G, et al: Notes from the field: Isolation of 2019-nCoV from a stool specimen of a laboratory-confirmed case of the coronavirus disease 2019 (COVID-19). China CDC Weekly 2: 123-124, 2020.

20. Jean SS, Lee PI and Hsueh PR: Treatment options for COVID-19: The reality and challenges. J Microbiol Immunol Infect 53: 436-443, 2020.

21. National Health Commission's briefing on the pneumonia epidemic situation. Released on May 4, 2020. http://www.nhc. gov.cn/xcs/yqfkdt/202005/9f8375d7ac9b4eda83515fcd5fd4adf4. shtml.

(i) $\odot$ This work is licensed under a Creative Commons Attribution-NonCommercial-NoDerivatives 4.0 International (CC BY-NC-ND 4.0) License. 